\title{
Reduction of MDR1, MRP1 and BCRP expression in Crohn's disease: a role in disease pathogenesis?
}

\section{ANA SAVIĆ MLAKAR ${ }^{1 \S}$ \\ ŽARKO BABIĆ ${ }^{2}$ \\ BRANKO TROSKOT ${ }^{3}$ \\ MLADEN JERGOVIĆ ${ }^{1}$ \\ VALERIJA VOJVODA PARČINA ${ }^{1}$ \\ ŽELJKO MIHALJEVIĆ ${ }^{4}$ \\ KREŠO BENDELJA ${ }^{1}$}

${ }^{1}$ Center for research and knowledge transfer in biotechnology, University of Zagreb, Croatia;

${ }^{2}$ Department of gastroenterology,

Clinical Hospital "Dubrava", School of Medicine,

University of Zagreb, Croatia;

${ }^{3}$ Department of gastroenterology,

Clinical Hospital "Sisters of Charity",

School of Medicine, University of Zagreb, Croatia;

${ }^{4}$ Croatian Veterinary Institute, Zagreb, Croatia

§Corresponding author: ASM: asavic@unizg.hr

Keywords: Crohn's disease; $A B C$ transporters; MRP1 (ABCC1); MDR1 (ABCB1); BCRP (ABCG2); Cytokines; Suppressors of cytokine signaling molecules (SOCS).
Received April 23, 2015.

Revised June 26, 2015.

Accepted July 04, 2015.

\begin{abstract}
Background and purpose: $A B C$ transporters have a non-redundant role in the maintenance of gut homeostasis and changes in their expression may contribute to the Crohn's disease pathology. As they are closely regulated by the inflammatory milieu, the coexpression of $A B C$ transporters, relevant proinflammatory cytokines and their negative regulators in the affected tissues could provide an insight to the pathological pattern of Crohn's disease related to different disease phases.
\end{abstract}

Materials and Methods: Crohn's disease patients were divided into three groups: newly diagnosed (untreated), active disease on therapy (treated) and remission. Intestinal mucosa from terminal ileum to rectum was compared to matching mucosa from healthy controls for $m R N A$ expression of MDR1, MRP1 and BCRP1. Affected terminal ileum and unaffected sigmoid colon mucosa were compared to controls for mRNA expression of relevant cytokines and suppressor of cytokine signaling molecules.

Results: MDRI mRNA expression is downregulated in inflamed tissues irrespective of patient groups. MRP1 expression is reduced in the untreated group and normalized after therapy introduction. Inflamed ileum was characterized by transitory increase in IFN- $\gamma, I L-17 A$ and SOCS3 expression in the treated group. In the unaffected colon, no significant difference in the expression of the tested transporters was observed, even though IFN- $\gamma, I L-2$ and $I L-1 \beta$ expression was increased.

Conclusion: Reduced MDR1 expression, irrespective of the disease group, and reduced MRP1 expression in untreated group, implicates the involvement of these transporters in the disease pathogenesis. The affected ileum lacks increased cytokine expression, while unaffected colon mucosa shows a Th1 cytokine profile.

\section{INTRODUCTION}

Crohn's disease (CD) is a chronic intestinal bowel disorder (IBD) of unknown cause in which genetic and environmental factors, primarily microbial, influence the gastrointestinal tract's ability to balance pro- and anti-inflammatory mechanisms. The immunopathology is driven by innate cytokines like TNF- $\alpha$, IL- 6 and IL- $1 \beta$ that are responsible for the chemokine release and neutrophil infiltration. Their production is elevated in $\mathrm{CD}$ and they contribute to tissue damage directly or indirectly through elevation of matrix metalloproteinases (1-3). Presence of elevated expression and production of cytokines like IFN- $\gamma$ and IL-17, produced by CD4 Th1 and Th17 effector T cells, implicate an ongoing adaptive immune response in the $\mathrm{CD}(4,5)$. 
The data on the possible involvement of ATP Binding Cassette $(\mathrm{ABC})$ transporters in the pathogenesis of Crohn's disease is inconclusive. Human gastrointestinal tract is continuously exposed to food antigens, commensal or pathogenic microbiota, all of which are kept in tight balance and interaction. Disruption of this balance ultimately leads to inflammation, as seen in IBD (6). ABC transporters form a part of the detoxification pathways, and are crucial in the maintenance of gut homeostasis and protection of epithelial cells from xenobiotics (7), and hence have a serious impact on the absorption and distribution of orally administered drugs (8). The $\mathrm{ABC}$ transporters MDR1 (P-glycoprotein, MDR1, encoded $A B C B 1$ ) and BCRP (Breast Cancer Resistance Protein, encoded $A B C G 2)$ are apical side localized transporters with a primary role in the efflux of potentially harmful xenobiotics from intestinal epithelial cells. MDR1 expression along human intestine is highest in the terminal ileum with lower and continuous levels throughout colon (9). Similar pattern of expression is observed for BCRP, with the highest expression in the terminal ileum, a continuous decrease along the colon, and $50 \%$ reduction at the sigmoid colon (10). However, MDR1 and BCRP expression is reduced in inflamed tissues of $\mathrm{CD}$ patients (11). MDR1 mRNA expression in inflamed tissue seems to be negatively regulated by the proinflammatory cytokines (11), which could also be the case for BCRP (12). The decrease in $\mathrm{ABC}$ transporter expression could have a direct implication on the disease pathology, as $m d r l a^{-1}$ mice develop spontaneous intestinal inflammation triggered by the normal bacterial flora that resembles human IBD (13). Moreover, double knock-out $\mathrm{mdr}^{-{ }^{--}}$and $\mathrm{t} \mid \mathrm{r} \mathrm{2}^{-{ }_{-}}$mice develop extensive colitis due to inefficient control of the nonpathogenic bacteria, confirming a protective function of MDR1 in antibacterial defense $(14,15)$. Studies on genetic polymorphisms of MDR1 in humans also implicate its involvement in the IBD pathogenesis (16).

The MRP1 (Multidrug resistance protein 1, encoded $A B C C 1$ ) is a basolateral multifunctional transporter. Varieties of different substrates of MRP1 have been determined showing preferential transport of amphiphilic anions, although conjugation with glutathione and sulfate increases substrate compatibility $(17,18)$. MRP1 transports endogenously produced compounds as well, bioactive lipids being one of the more intriguing ones. Additionally, it is essential for transport of leukotrienes, for example leukotriene C4 (LTC4), which is important pro-inflammatory lipid mediator implicated in IBD pathology (19). Besides its function in the transport of different toxic substrates, MRP1 transports reduced glutathione (GSH) and its oxidized derivates like glutathione disulfide (GSSG), S-nitrosoglutathione (GS-NO) and glutathione-metal complexes $(20,21)$. GSH represents the most important detoxifying and anti-oxidative intestine pathway. Blockade of GSH synthesis causes massive degeneration of epithelial cells in the small intestine and colon (22). As MRP1 can regulate levels of GSH and oxidized GSH derivates (23), it is also involved in direct control of redox homeostasis and prevention of apoptosis of intestinal epithelial cells (24). MRP1 is equally expressed in all intestinal regions (25), and its expression in IBD seems to be upregulated (24). Recent findings suggest that mrp1-/- mice treated with DSS develop more severe colitis due to extensive epithelial damage (26).

The first line treatment of $\mathrm{CD}$ includes drugs that are substrates of $A B C$ transporters - for example glucocorticoids, which are effluxed by MDR1 (27), and sulfasalazine, effluxed by BCRP (28). Overexpression or increased activity of these transporters could have an impact on the therapy outcome, as is the case of steroid resistance in IBD (29).

In this study we aimed to determine the mRNA expression of MDR1, MRP1 and BCRP in the terminal ileum and colon of $\mathrm{CD}$ patients (untreated, treated and remission) and healthy controls. In addition, the expression of IFN- $\gamma$, IL-2, IL-6, IL-1 $\beta$ and IL-17A, as well as two suppressors of cytokine signaling molecules (SOCS1 and SOCS3) were determined in the inflamed terminal ileum and sigmoid colon, as an increase in number and diameter of lymphoid aggregates in unaffected colonic tissues from $\mathrm{CD}$ patients has been observed $(30,31)$. Changes in the expression of cytokines and SOCS molecules at different stages of the disease could provide further information on disease pathogenesis. Additionally, knowing the exact expression profiles of $\mathrm{ABC}$ transporters in human gastrointestinal tract could be useful in CD therapy design.

\section{METHODS}

\section{Patients and samples}

Punch biopsy specimens from six different locations (terminal ileum, ascending colon, transverse c., descending c., sigmoid c. and rectum) were taken from $25 \mathrm{CD}$ (average age 43.46 \pm 13.77 ) patients during routine colonoscopy. The diagnosis was based on classic clinical features, as well as endoscopic, pathohistological and laboratory findings. Patients were divided into three groups based on the disease status:newly diagnosed (untreated), patients with active inflammation under therapy (treated) and patients in remission. Control samples were taken from non-IBD patients who undertook colonoscopy for clinical investigation of rectal bleeding, anaemia or functional disorders like Irritable Bowel Syndrome (IBS) $(n=10$; average age $57.86 \pm 17.4)$. The expression of cytokines and SOCS molecules were determined at inflamed terminal ileum and unaffected sigmoid colon. Control biopsies were compared to patient's biopsies from the same site. Patient's characteristics are presented in Table 1. The informed consent was obtained from all participants prior to inclusion and the protocol was approved by the Ethics Committees of University hospitals "Sisters of Charity" and "Dubrava", Zagreb, Croatia. Samples were immediately immerged into a tube with RNAlater solu- 
tion (Ambion, Foster City, United States) for the preservation of the RNA and left overnight at $+4^{\circ} \mathrm{C}$ so that the solution could uniformly penetrate the tissue. Supernatant was removed and samples were stored at $-80^{\circ} \mathrm{C}$ until further processing.

\section{RNA isolation}

Samples from each intestinal region were homogenised in RLT buffer for 20-30 seconds (T25basic, IKA Labortechnik, Germany) and total cellular RNA was isolated using RNeasy Kit (Qiagen, Hilden, Germany) following protocol provided by the manufacturer. The purity and concentration of extracted total RNA was determined with Bio Photometer (Eppendorf, Hamburg, Germany) at $\mathrm{A}_{260 / 280}$.

\section{Reverse transcription}

2ug of total RNA was reverse-transcribed using High Capacity cDNA Reverse Transcription Kit with RNAse inhibitor (Applied Biosystems, Foster City, United States) using protocol provided by the manufacturer, with random hexamers as primers. The conditions of reverse transcription reaction were: $25^{\circ} \mathrm{C} / 10 \mathrm{~min}, 37^{\circ} \mathrm{C} / 120 \mathrm{~min}$, $85^{\circ} \mathrm{C} / 5 \mathrm{~min}, 4^{\circ} \mathrm{C} / \infty$. cDNA was stored at $-20^{\circ} \mathrm{C}$ until further processing.

\section{TaqMan analysis}

Quantitative PCR of samples was performed on 7500 Real-Time PCR System (Applied Biosystems) under follow- ing thermal cycling conditions: $95^{\circ} \mathrm{C} / 10 \mathrm{~min}, 40$ cycles 95 ${ }^{\circ} \mathrm{C} / 15 \mathrm{~s}, 60^{\circ} \mathrm{C} / 1 \mathrm{~min}$. TaqMan Gene Expression Master Mix and TaqMan Gene Expression Assays for examined genes (MDR1 Hs00184491_m1, MRP1 Hs00219905_ m1, BCRP Hs00184797_m1, IFN- $\gamma$ Hs00989291_m1, IL-2 Hs01555413_m1, IL-6 Hs00985641_m1, IL-1 $\beta$ Hs00174383_m1, IL-17 Hs00174114_m1, SOCS1 Hs00705164_s1 and SOCS3 Hs02330328_s1) were used following manufacturer's protocol. GAPDH (Applied Biosystems) served as endogenous control. Samples were run in triplicates and no template control (NTC) was used as negative control for each gene. Data were collected and analysed with the 7500 System SDS Software.

Statistics: Data were analysed using the comparative Ct method (the $\Delta \Delta \mathrm{Ct}$ method) and the results are presented as transcript levels relative to levels in controls. After assessment of data normality by Shapiro-Wilk W test, and subsequent logarithmic transformation of nonnormally distributed variables, the expression of examined molecules in each segment of the intestine of CD patients were compared with that of control subjects by a multivariable regression analysis. Age, sex and concomitant treatment of CD patients were considered as potential confounding factors. The Kendall-tau correlation coefficient was calculated to analyse the correlation between mRNA expression of $\mathrm{ABC}$ transporters and that of examined cytokines and SOCS molecules. All statistical analyses were performed using STATA 13.0 (StataCorp. 2013. Stata Statistical Software: Release 13. College Station, TX: StataCorp LP).

Table 1. Patients characteristics

\begin{tabular}{|c|c|c|c|c|}
\hline & Controls $(\mathrm{N}=10)$ & $\mathrm{CD}$ (untreated) $(\mathrm{N}=8)$ & $\mathrm{CD}$ (treated) $(\mathrm{N}=9)$ & $\mathrm{CD}$ (remission) $(\mathrm{N}=8)$ \\
\hline \multicolumn{5}{|l|}{ Gender } \\
\hline Female & 1 & 4 & 3 & 3 \\
\hline Male & 9 & 4 & 6 & 5 \\
\hline Mean age, yr. $\pm S D$ & $57.86 \pm 17.4$ & $41.38 \pm 11.46$ & $40.22 \pm 13.78$ & $46.88 \pm 16.87$ \\
\hline \multicolumn{5}{|l|}{ Extend of disease } \\
\hline \multicolumn{5}{|l|}{$\mathrm{CD}$} \\
\hline Ileal & - & 8 & 9 & 8 \\
\hline Ileocolic & - & - & - & - \\
\hline Colon & - & - & - & - \\
\hline \multicolumn{5}{|l|}{ Therapy } \\
\hline 5-aminosalicylates & - & - & 7 & 6 \\
\hline Corticosteroids & - & - & 5 & 3 \\
\hline Immunesuppressives & - & - & 4 & 3 \\
\hline Biologicals & - & - & - & - \\
\hline None & 10 & 8 & - & - \\
\hline \multicolumn{5}{|c|}{ Pathological severity (CDAI) } \\
\hline remission & - & - & - & 8 \\
\hline mild & - & - & - & - \\
\hline moderate & - & 7 & 7 & - \\
\hline severe & - & 1 & 2 & - \\
\hline
\end{tabular}


A.

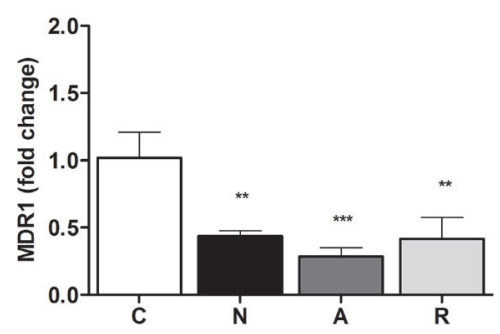

c.

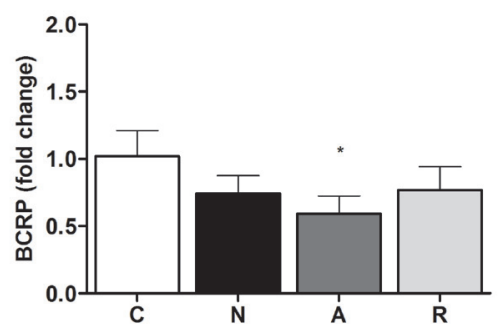

B.

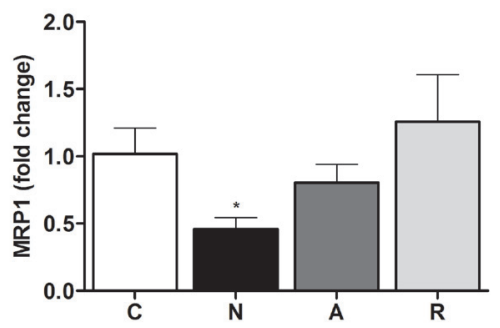

\section{RESULTS}

\section{Expression of ABC transporters}

MDR1 and BCRP mRNA expression along the examined intestinal locations in patients and healthy controls exhibits the same pattern, showing the highest expression at terminal ileum compared to the colon and rectum. There is also no difference in MRP1 mRNA expression pattern between patients and healthy controls or along intestine (data not shown).

A statistical analysis shows that in the inflamed ileum the mRNA expression of MDR1 was reduced in CD pa-
Figure 1. Transporter expression in CD patients at inflamed terminal ileum. The expression values of MDR1, MRP1 and BCRP are normalized to the housekeeping gene GAPDH and are presented relative to the matched locations of the controls. Data are presented as mean \pm SEM and statistically significant differences are indicated by ${ }^{*} p<0,05,{ }^{* *} p<0,01$ and ${ }^{* * *} p<$ 0,001. Black bars $=N$ group (untreated); dark grey $=$ A group (treated); light grey $=R$ group (remission); open bars = controls.
A.

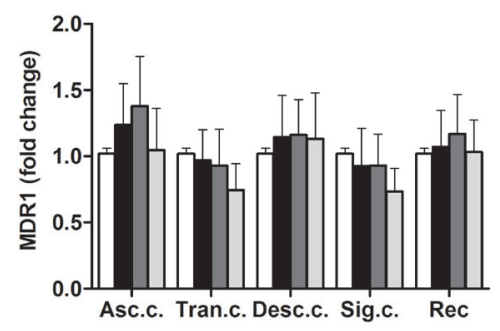

C.

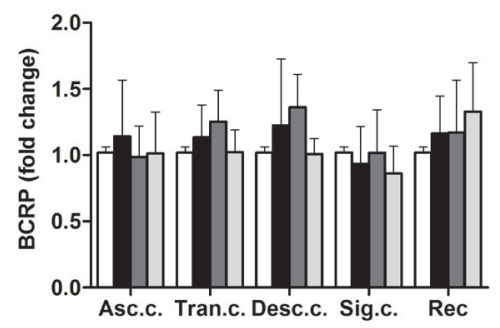

B.

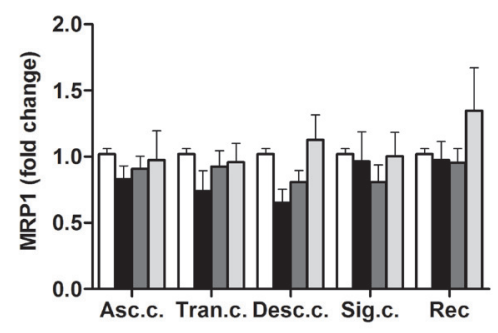

tients, by $56 \%, 72 \%$ and $58 \%$ in untreated, treated and remission group, when compared to healthy controls (Figure $1 \mathrm{~A})$. Neither the therapeutical intervention nor the achievement of the disease remission altered the downregulated MDR1 mRNA expression in ileum tissue from CD patients.

The MRP1 mRNA expression was reduced by $54 \%$ in ileum tissues of untreated CD patients compared to healthy controls. Introduction of a therapy increased MRP1 mRNA to healthy levels that sustained into the remission phase (Figure 1B). The reduction of BCRP

Figure 2. Transporter expression in CD patients at unaffected colon. The expression values of MDR1, MRP1 and BCRP are normalized to the housekeeping gene GAPDH and are presented relative to the matched locations of the controls. Data are presented as mean \pm SEM. Black bars $=N$ group (untreated); dark grey $=A$ group (treated); light grey $=R$ group (remission); open bars $=$ controls. 
A.

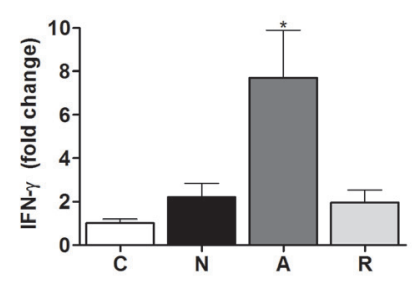

D.

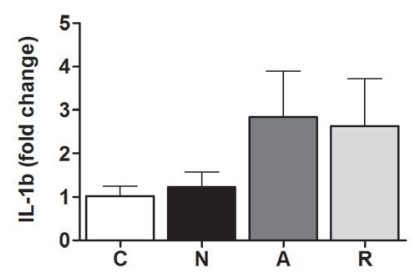

G.

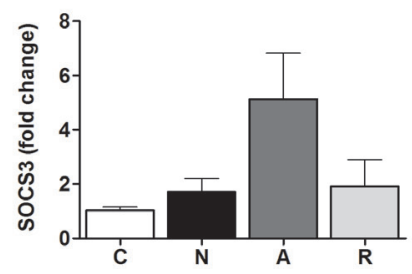

B.

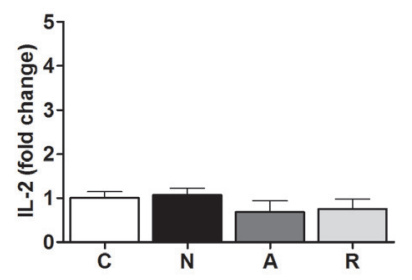

E.

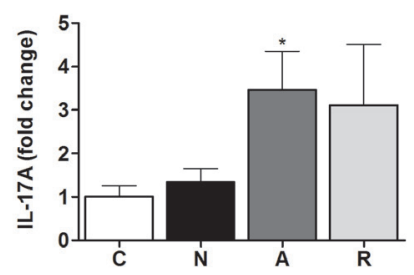

c.

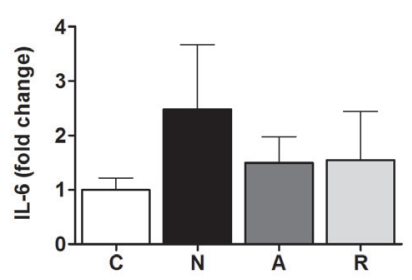

F.

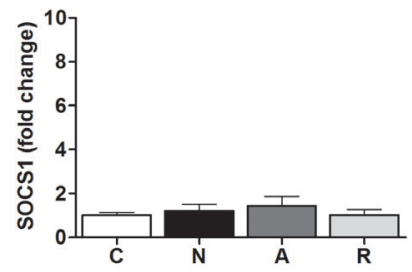

Figure 3. Cytokine and SOCS expression in the inflamed ileum of CD patients. The expression values of $I F N-\gamma, I L-2, I L-6, I L-1 \beta, I L-$ $17 A$, SOCS1 and SOCS3 are normalized to the housekeeping gene GAPDH and are presented relative to the matched locations of the controls. Data are presented as mean \pm SEM and statistically significant differences are indicated by ${ }^{*} p<0,05$. Black bars $=N$ group (untreated); dark grey $=$ A group (treated); light grey $=$ R group (remission); open bars = controls.

mRNA expression in untreated patients was borderline significant $(\mathrm{p}=0,070)$, while in treated group was reduced by $41 \%$ (Figure $1 C$ ). In remission the mRNA BCRP levels were within range of healthy controls.

Also, there were only minor differences in the expression levels of all three transporters throughout the unaffected colon between CD patients and healthy controls.

\section{Expression of cytokines and SOCs molecules}

At the inflamed terminal ileum of untreated CD patients, no significant difference in analysed cytokines or SOCS mRNA levels were detected (Figure 3A-G). Treatment transiently increased IFN- $\gamma$, IL-17A and SOCS3 mRNA expression (7-fold, 3.5-fold and 5-fold, respectively) when compared to healthy subjects and patients in remission. There were no significant differences for mRNA expression levels of IL-6, IL-1 $\beta$ and SOCS1 between defined CD groups and healthy subjects.

In contrast to inflamed terminal ileum, the levels of IFN- $\gamma$, IL- 2 and IL- $1 \beta$ mRNA at the unaffected sigmoid colon tissue were higher in untreated patients, with clear decrease on therapy introduction to the levels of healthy controls (Figure 4A-B,D).

In the remission group of patients, the levels of IFN- $\gamma$ and IL- 2 mRNA were higher again, while IL- $1 \beta$ mRNA remained at low levels. The expression of IL-17A at the unaffected colon was also elevated but reached a statistical significance only in the remission group (3.4-fold higher expression) (Figure 4E). Like in the inflamed ileum, there were no differences in IL-6 expression among the defined groups at unaffected colon (Figure 4C). The levels of SOCS1 and SOC3 mRNA at the unaffected sigmoid colon tissue of CD patients followed the same pattern as found for IFN- $\gamma$ and IL-2 being higher in untreated patients, decreased in treated group and increased in remission, respectively (Figure 4.). In comparison to affected ileum, mRNA levels of SOCS1 were significantly higher in unaffected colon tissue.

\section{DISCUSSION}

Efflux transporters contribute to the maintenance of gut homeostasis and hence to the intact gut barrier. Their role in the pathogenesis of IBD is controversial and to date 
A.

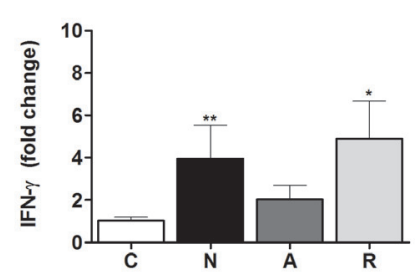

D.

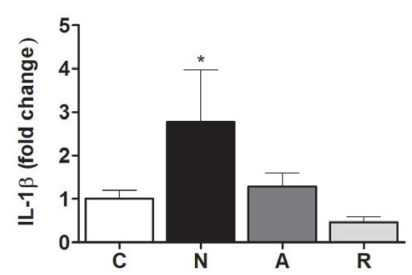

G.

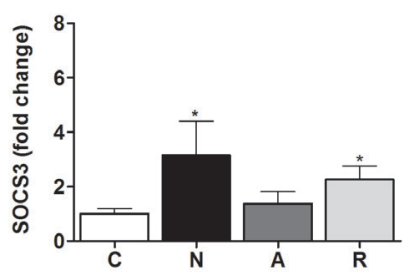

B.
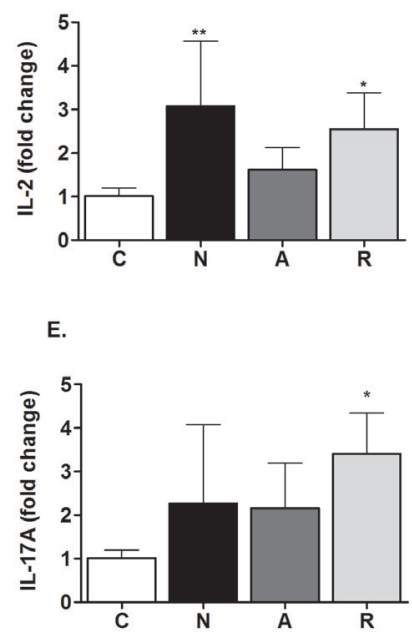

C.

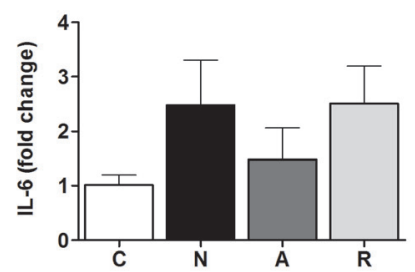

F.

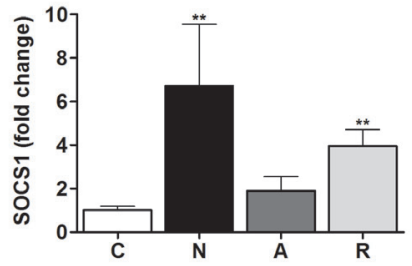

Figure 4. Cytokine and SOCS expression in the unaffected colon of CD patients. The expression values of IFN- $\gamma, I L-2, I L-6, I L-1 \beta$, $I L-17 A, S O C S 1$ and SOCS3 are normalized to the housekeeping gene GAPDH and are presented relative to the matched locations of the controls. Data are presented as mean \pm SEM and statistically significant differences are indicated by ${ }^{*} p<0,05$. Black bars $=N$ group (untreated); dark grey = A group (treated); light grey = R group (remission); open bars = controls.

only a few studies examined the expression profiles of multiple efflux transporters simultaneously. Zimmerman et al. determined MDR1 and MRP1-5 transporter expression from duodenum to sigmoid colon and provided important data on site-specific expression, but the samples were taken only from healthy subjects (9).

In the present study, we determined the expression profiles of MDR1, MRP1 and BCRP from terminal ileum to rectum in three groups of patients, each corresponding to different disease phase, and matched tissue from healthy controls. The pattern of expression of all three transporters, with the highest expression at terminal ileum for MDR1 and BCRP, and constant expression for MRP1 along intestine, are similar between healthy and diseased subjects.

The expression level of MDR1 in CD patients is generally reduced, regardless of the disease phase. This overall reduction seems to be characteristic only for the inflamed ileum, since there were no differences in MDR1 expression along the unaffected colon. Functional consequence of downregulated MDR1 on IBD pathology was confirmed by Panwala et al. in a study using mdrla $\mathrm{a}^{-/-}$mice that developed spontaneous intestinal inflammation (13). This indicates that a loss of the efflux capacities of the gut may promote the development of colitis. However, it has been shown that MDR1 interferes with bacterial adhesion to enterocytes and reduces the risk of gastrointestinal disorders (15). Interestingly, at the same time, mdrla-/- mice display reduced expression of regenerating islet-derived protein 3 gamma (REG3G) in intestinal mucosa (32). REG3G prevents exaggerated inflammation by bactericidal activity and suppression of cytokine production (33). The interplay of MDR1 and REG3G in the balance of intestinal homeostasis is still unknown, but both are regulated by microbial colonization (34). Downregulated MDR1 expression in the ileum is in conflict with increased REG3G expression in CD patients by Gironella et all (33) and assume different regulatory mechanisms. The observed overall reduction in MDR1 expression makes it a possible candidate in the $\mathrm{CD}$ pathogenesis and points to a certain physiological role, possibly through modulation of interactions with commensals and antimicrobials.

The expression of BCRP in the inflamed tissue is similar to MDR1, with reduced expression during treatment, although the reduction in its expression in untreated $C D$ group was borderline significant $(\mathrm{p}=0.070)$. This might be explained by the fact that suphasalazine and metho- 
trexate, the common therapeutics for IBD, are known to raise homocysteine levels and lower folate levels, which ultimately results in the downregulation of BCRP expression (35). With the resolution of inflammation, the BRCP expression normalized to control values. Furthermore, we have found that patients treated with aminosalicylates had considerably lower expression of MDR1 $(\mathrm{p}=0.008)$ and BCRP ( $p=0.045)$. It is known that BCRP and MRP1 are responsible for the efflux of glutathione (GSH) and its conjugated forms (36) and thus participate in the maintenance of intracellular redox status. Our results have shown that MRP1 expression was reduced in untreated $\mathrm{CD}$ group and normalized after resolution of inflammation. The reduced expression of MRP1, as well as BCRP, in ileal tissues of CD patients might affect efflux of ROS outside epithelial cells, rendering them more sensitive to apoptosis by Fas ligand and $\mathrm{LTC}_{4}(24,37)$. Furthermore, Hove et al (26) shows that mrp1-/- mice treated with DSS develop more severe disease caused by severe epithelial damage, confirming a MRP1 role in IBD pathogenesis.

Several studies on various animal models showed that ongoing inflammatory responses have an impact on MDR1 and BCRP mRNA expression and function (38), which was also found to be true in humans (11). We have now found that the inflamed ileum of CD patients did not show the expected cytokine profile with elevated expression of IFN- $\gamma$ in the affected ileal tissue. However, we have found increased IFN- $\gamma$ expression in the treated group, which might have resulted from sulphasalazine treatment that can up-regulate the expression of IFN- $\gamma$ (39). Furthermore, there was no difference in IL-6 or IL$1 \beta$ expression among the defined groups, although IL- 6 was borderline significantly elevated in the untreated group $(p=0.0625)$. Unexpectedly, the treatment transiently increased IL-17A mRNA levels in the remission group. IL-17A has been linked to the pathology of CD, intensifying the potent mechanisms of innate immunity (40). It is regulated by IL-23, but the same cytokine is required for induction of counteractive IL-22, which has a protective role in CD (41), However, we did not measure IL-22 expression in order to determine the IL-17A/IL-22 ratio. It is possible that the obvious lack of elevated expression of examined cytokines in inflamed tissue of CD patients can be explained by the presence of elevated expression of other inflammatory cytokines that were not included in the study, particularly TNF- $\alpha$, which is known to be elevated and a target of successful anti-TNF$\alpha$ therapy (42). Lack of increased IL-1 $\beta$ and IL-17A levels is in line with ineffectiveness of anti-cytokines monoclonal antibody treatments in CD $(43,44)$.

As SOCS molecules provide crucial negative feedback on the cytokine signaling, they might play a relevant role in the control of mucosal damage in IBD patients (45). Our results show that, in the inflamed tissue, there were no differences in SOCS1 expression between the defined groups. It is known that SOCS1 negatively regulates
STAT1 pathway in the murine IBD model (46). Furthermore, SOCS1 is regulator of TNF- $\alpha$ and the lack of its elevated expression in the inflamed CD ileum might further contribute to ongoing TNF- $\alpha$ mediated inflammation. On the other hand, an increase of SOCS3 mRNA levels in inflamed tissues of treated patients follows kinetics of IFN- $\gamma$ and IL-17A expression. Higher levels of SOCS3 expression have been detected in the colon of IBD patients (47) and might be a result of the feed-back regulation of STAT3 activation. SOCS3 has been proposed to balance between mucosal wound healing and hyperplasia (48) and a higher SOCS3 expression at the remission could predict mucosal relapse (49).

In contrast to the inflamed ileum, increased IFN- $\gamma$ and IL-2 mRNA expression levels was detected in the unaffected colon of the untreated group. Their expression normalized to healthy levels in the treated group, but regained upregulated expression in remission. IL-1 $\beta$ levels were also elevated in the untreated group, but normalized to control values after resolution of inflammation. This data demonstrate that the unaffected sigmoid colon in CD patients is characterized by the Th1 cytokine profile and elevated innate IL- $1 \beta$ expression, as is commonly observed for CD. Interestingly, higher expression values of both SOCS1 and SOCS3 were found in the unaffected colon of CD patients which were accompanied by increased IFN- $\gamma$, IL-2, and IL-1 $\beta$ expression. High SOCS1 and SOCS3 expression in the unaffected areas of the untreated group could be the reason why the unaffected areas do not display histological alternations in spite of the higher cytokine expression. Overall, our results indicate that unaffected gastrointestinal tract tissue of CD patients differs from that of healthy controls. Our finding of deregulated cytokine production, together with the Nascimbeni et al. observation of formation of lymphoid aggregates in unaffected tissues, address a possible important role in the disease pathology (50). In the present study we show general reduction in MDR1 expression in CD. Involvement of MRP1 in CD pathogenesis is plausible, but further research is needed. Furthermore, our results demonstrate a lack of the expected Th1 cytokine profile in the inflamed tissue of CD patients. In contrast, the unaffected colon was characterized by increased expressions of the cytokines and SOCS molecules. The potential functional importance of altered transporter expression in disease progression and the involvement of therapy should be further explored.

\section{REFERENCES}

1. Puleston J, Cooper M, Murch S, Bid K, Makh S, Ashwood P, et al.: A distinct subset of chemokines dominates the mucosal chemokine response in inflammatory bowel disease. Aliment Pharmacol Ther 2005 Jan 15;21:109-20. http://dx.doi.org/10.1111/j.1365-2036. 2004.02262.x

2. Alzoghaibi MA: Neutrophil expression and infiltration into Crohn's intestine. Saudi J Gastroenterol 2005 May;11:63-72. http://dx.doi. org/10.4103/1319-3767.33322 
3. Pallone F, Monteleone G: Mechanisms of tissue damage in inflammatory bowel disease. Curr Opin Gastroenterol 2001 Jul;17:307-12. http://dx.doi.org/10.1097/00001574-200107000-00002

4. Duchmann R, Kaiser I, Hermann E, Mayet W, Ewe K, Meyer zum Büschenfelde $\mathrm{KH}$ : Tolerance exists towards resident intestinal flora but is broken in active inflammatory bowel disease (IBD). Clin Exp Immunol 1995 Dec;102:448-55. http://dx.doi.org/10.1111/j.13652249.1995.tb03836.x

5. Fujino S, Andoh A, Bamba S, Ogawa A, Hata K, Araki Y, et al.: Increased expression of interleukin 17 in inflammatory bowel disease. Gut 2003 Jan;52:65-70. http://dx.doi.org/10.1136/gut.52.1.65

6. Miyauchi E, Morita H, Okuda J, Sashihara T, Shimizu M, Tanabe S: Cell wall fraction of Enterococcus hirae ameliorates TNF-alphainduced barrier impairment in the human epithelial tight junction. Lett Appl Microbiol 2008 Apr;46:469-76. http://dx.doi.org/10.1111/ j.1472-765X.2008.02332.x

7. Dietrich $\mathrm{CG}: \mathrm{ABC}$ of oral bioavailability: transporters as gatekeepers in the gut. Gut 2003 Dec 1;52:1788-1795. http://dx.doi.org/10.1136/ gut.52.12.1788

8. Ambudkar S V, Dey S, Hrycyna C a, Ramachandra M, Pastan I, Gottesman MM: Biochemical, cellular, and pharmacological aspects of the multidrug transporter. Annu Rev Pharmacol Toxicol 1999 Jan;39:361-98. http://dx.doi.org/10.1146/annurev.pharmtox.39.1.361

9. Zimmermann C, Gutmann H, Hruz P, Gutzwiller J-P, Beglinger $\mathrm{C}$, Drewe J, et al.: Mapping of multidrug resistance gene 1 and multidrug resistance-associated protein isoform 1 to $5 \mathrm{mRNA}$ expression along the human intestinal tract. Drug Metab Dispos 2005 Feb;33:219-224. http://dx.doi.org/10.1124/dmd.104.001354

10. Gutmann H, Hruz P, Zimmermann C, Beglinger C, Drewe J: Distribution of breast cancer resistance protein (BCRP/ABCG2) mRNA expression along the human GI tract. Biochem Pharmacol 2005 Sep 1;70:695-9. http://dx.doi.org/10.1016/j.bcp.2005.05.031

11. Blokzijl H, Vander Borght $S$, Bok LIH, Libbrecht L, Geuken M, van Den Heuvel FAJ, et al.: Decreased P-glycoprotein (P-gp/MDR1) expression in inflamed human intestinal epithelium is independent of PXR protein levels. Inflamm Bowel Dis 2007 Jun;13:710-20. http://dx.doi.org/10.1002/ibd.20088

12. Englund et al: Efflux Transporters in Ulcerative Colitis Decreased Expression of BCRP (ABCG2) and Pgp (ABCB1). Inflamm Bowel Dis 2007;13:291-297. http://dx.doi.org/10.1002/ibd.20030

13. Panwala CM, Jones JC, Viney JL: A novel model of inflammatory bowel disease: mice deficient for the multiple drug resistance gene, mdrla, spontaneously develop colitis. J Immunol 1998 Nov 15; 161:5733-44.

14. Ey B, Eyking A, Klepak M, Salzman NH, Göthert JR, Rünzi M, et al.: Loss of TLR2 worsens spontaneous colitis in MDR1A deficiency through commensally induced pyroptosis. J Immunol 2013 Jun 1;190:5676-88. http://dx.doi.org/10.4049/jimmunol.1201592

15. Crowe A: The role of P-glycoprotein and breast cancer resistance protein (BCRP) in bacterial attachment to human gastrointestinal cells. J Crohns Colitis 2011 Dec;5:531-42. http://dx.doi. org/10.1016/j.crohns.2011.05.002

16. Brinar M, Cukovic-Cavka S, Bozina N, Ravic KG, Markos P, Ladic A, et al.: MDR1 polymorphisms are associated with inflammatory bowel disease in a cohort of Croatian IBD patients. BMC Gastroenterol 2013 Jan;13:57. http://dx.doi.org/10.1186/1471-230X-13-57

17. Cole SP, Bhardwaj G, Gerlach JH, Mackie JE, Grant CE, Almquist $\mathrm{KC}$, et al.: Overexpression of a transporter gene in a multidrug-resistant human lung cancer cell line. Science 1992 Dec 4;258:16504. http://dx.doi.org/10.1126/science.1360704

18. Hipfner DR, Deeley RG, Cole SP: Structural, mechanistic and clinical aspects of MRP1. Biochim Biophys Acta 1999 Dec 6;1461:359-76. http://dx.doi.org/10.1016/S0005-2736(99)00168-6
19. Van Dullemen H, Meenan J, Stronkhorst A, Tytgat GN, van Deventer SJ: Mediators of mucosal inflammation: implications for therapy. Scand J Gastroenterol Suppl 1997 Jan;223:92-8.

20. Ellison I, Richie JP: Mechanisms of glutathione disulfide efflux from erythrocytes. Biochem Pharmacol 2012 Jan 1;83:164-9. http:// dx.doi.org/10.1016/j.bcp.2011.09.016

21. Ballatori N, Krance SM, Marchan R, Hammond CL: Plasma membrane glutathione transporters and their roles in cell physiology and pathophysiology. Mol Aspects Med Jan;30:13-28.

22. Mårtensson J, Jain A, Meister A: Glutathione is required for intestinal function. Proc Natl Acad Sci U S A 1990 Mar;87:1715-9. http:// dx.doi.org/10.1073/pnas.87.5.1715

23. Iantomasi $\mathrm{T}$, Marraccini P, Favilli F, Vincenzini MT, Ferretti P, Tonelli F: Glutathione metabolism in Crohn's disease. Biochem Med Metab Biol 1994 Dec;53:87-91. http://dx.doi.org/10.1006/ bmmb.1994.1062

24. Blokzijl H, van Steenpaal A, Vander Borght S, Bok LIH, Libbrecht L, Tamminga M, et al.: Up-regulation and cytoprotective role of epithelial multidrug resistance-associated protein 1 in inflammatory bowel disease. J Biol Chem 2008 Dec 19;283:35630-7. http://dx. doi.org/10.1074/jbc.M804374200

25. Berggren S, Gall C, Wollnitz N, Ekelund M, Karlbom U, Hoogstraate J, et al.: Gene and protein expression of P-glycoprotein, MRP1, MRP2, and CYP3A4 in the small and large human intestine. Mol Pharm 2007;4:252-7. http://dx.doi.org/10.1021/ mp0600687

26. Hove T Ten, Drillenburg P, Wijnholds J, Velde AA te, Deventer SJH van: Differential Susceptibility of Multidrug Resistance Protein-1 Deficient Mice to DSS and TNBS-Induced Colitis. Dig Dis Sci47:2056-2063. http://dx.doi.org/10.1023/A:1019629013945

27. Dilger K, Schwab M, Fromm MF: Identification of budesonide and prednisone as substrates of the intestinal drug efflux pump P-glycoprotein. Inflamm Bowel Dis 2004 Sep;10:578-83. http://dx.doi. org/10.1097/00054725-200409000-00012

28. Zaher H, Khan AA, Palandra J, Brayman TG, Yu L, Ware JA: Breast Cancer Resistance Protein (Bcrp/abcg2) Is a Major Determinant of Sulfasalazine Absorption and Elimination in the Mouse. Mol Pharm 2006 Feb;3:55-61. http://dx.doi.org/10.1021/mp050113v

29. Podolsky D: Inflammatory bowel disease. $\mathrm{N}$ Engl J Med 2002;347:417-429. http://dx.doi.org/10.1056/NEJMra020831

30. Shah N, Thakkar B, Shen E, Loh M, Chong PY, Gan WH, et al.: Lymphocytic follicles and aggregates are a determinant of mucosal damage and duration of diarrhea. Arch Pathol Lab Med 2013 Jan;137:83-9. http://dx.doi.org/10.5858/arpa.2011-0430-OA

31. Jung C, Hugot J-P, Barreau F: Peyer's Patches: The Immune Sensors of the Intestine. Int J Inflam 2010 Jan;2010:823710.

32. Collett A, Higgs NB, Gironella M, Zeef LAH, Hayes A, Salmo E, et al.: Early molecular and functional changes in colonic epithelium that precede increased gut permeability during colitis development in mdr1a(-/-) mice. Inflamm Bowel Dis 2008 May;14:620-31. http://dx.doi.org/10.1002/ibd.20375

33. Gironella M, Iovanna JL, Sans M, Gil F, Peñalva M, Closa D, et al.: Anti-inflammatory effects of pancreatitis associated protein in inflammatory bowel disease. Gut 2005 Sep;54:1244-53. http://dx.doi. org/10.1136/gut.2004.056309

34. Saksena S, Goyal S, Raheja G, Singh V, Akhtar M, Nazir TM, et al.: Upregulation of P-glycoprotein by probiotics in intestinal epithelial cells and in the dextran sulfate sodium model of colitis in mice. Am J Physiol Gastrointest Liver Physiol 2011 Jun;300:G1115-23. http:// dx.doi.org/10.1152/ajpgi.00027.2011

35. Ifergan I, Shafran A, Jansen G, Hooijberg JH, Scheffer GL, Assaraf YG: Folate Deprivation Results in the Loss of Breast Cancer Resistance Protein (BCRP/ABCG2) Expression. Biochemistry 2004;279: 25527-25534. 
36. Rothnie A, Conseil G, Lau AYT, Deeley RG, Cole SPC: Mechanistic differences between GSH transport by multidrug resistance protein 1 (MRP1/ABCC1) and GSH modulation of MRP1-mediated transport. Mol Pharmacol 2008;74:1630-1640. http://dx.doi. org/10.1124/mol.108.049080

37. Wang L, Azad N, Kongkaneramit L, Chen F, Lu Y, Jiang B-H, et al.: The Fas death signaling pathway connecting reactive oxygen species generation and FLICE inhibitory protein down-regulation. J Immunol 2008 Mar 1;180:3072-80. http://dx.doi.org/10.4049/ jimmunol.180.5.3072

38. Kalitsky-Szirtes J, Shayeganpour A, Brocks DR, Piquette-Miller M: Suppression of drug-metabolizing enzymes and efflux transporters in the intestine of endotoxin-treated rats. Drug Metab Dispos 2004 Jan;32:20. http://dx.doi.org/10.1124/dmd.32.1.20

39. Ding H, Mei Q, Gan H-Z, Cao L-Y, Liu X-C, Xu J-M: Effect of homocysteine on intestinal permeability in rats with experimental colitis, and its mechanism. Gastroenterol Rep 2014. http://dx.doi. org/10.1093/gastro/gou022

40. Jovanovic D V, Di Battista JA, Martel-Pelletier J, Jolicoeur FC, He Y, Zhang M, et al.: IL-17 stimulates the production and expression of proinflammatory cytokines, IL-beta and TNF-alpha, by human macrophages. J Immunol 1998 Apr 1;160:3513-21.

41. Li L-J, Gong C, Zhao M-H, Feng B-S: Role of interleukin-22 in inflammatory bowel disease. World J Gastroenterol 2014 Dec 28;20:18177-18188. http://dx.doi.org/10.3748/wjg.v20.i48.18177

42. Reimund J-M, Ratajczyk J, Sola B, Justum A-M, Muller CD: Antitumor necrosis factor-alpha (TNF-alpha) treatment strategies in Crohn's disease. Recent Pat Inflamm Allergy Drug Discov 2007 Feb;1:21-34. http://dx.doi.org/10.2174/187221307779815093

43. Cardani D, Dusio GF, Luchini P, Sciarabba M, Solimene U, Rumio C: Oral Administration of Interleukin-10 and Anti-IL-1 Antibody
Ameliorates Experimental Intestinal Inflammation. Gastroenterol Res 2013 Sep 9;6:124-133. http://dx.doi.org/10.4021/gr556w

44. Hueber W, Sands BE, Lewitzky S, Vandemeulebroecke M, Reinisch W, Higgins PDR, et al.: Secukinumab, a human anti-IL-17A monoclonal antibody, for moderate to severe Crohn's disease: unexpected results of a randomised, double-blind placebo-controlled trial. Gut 2012 Dec;61:1693-700. http://dx.doi.org/10.1136/gutjnl-2011301668

45. Horino J, Fujimoto M, Terabe F, Serada S, Takahashi T, Soma Y, et al.: Suppressor of cytokine signaling- 1 ameliorates dextran sulfate sodium-induced colitis in mice. Int Immunol 2008 Jun;20:753-62. http://dx.doi.org/10.1093/intimm/dxn033

46. Chinen T, Kobayashi T, Ogata H, Takaesu G: Suppressor of cytokine signaling-1 regulates inflammatory bowel disease in which both IFN- $\beta$ and IL- 4 are involved. Gastroenterology 2006;373-388. http://dx.doi.org/10.1053/j.gastro.2005.10.051

47. Schreiber S, Rosenstiel P, Hampe J, Nikolaus S, Groessner B, Schottelius A, et al.: Activation of signal transducer and activator of transcription (STAT) 1 in human chronic inflammatory bowel disease. Gut 2002 Sep;51:379-85. http://dx.doi.org/10.1136/gut.51.3.379

48. Tebbutt NC, Giraud AS, Inglese M, Jenkins B, Waring P, Clay FJ, et al.: Reciprocal regulation of gastrointestinal homeostasis by SHP2 and STAT-mediated trefoil gene activation in gp130 mutant mice. Nat Med 2002 Oct;8:1089-97. http://dx.doi.org/10.1038/nm763

49. Li Y, Nuij VJAA, Baars JE, Biermann K, Kuipers EJ, Peppelenbosch MP, et al.: Increased suppressor of cytokine signaling-3 expression predicts mucosal relapse in ulcerative colitis. Inflamm Bowel Dis 2013 Jan;19:132-40. http://dx.doi.org/10.1002/ibd.22992

50. Nascimbeni R, Di Fabio F, Di Betta E, Mariani P, Fisogni S, Villanacci V: Morphology of colorectal lymphoid aggregates in cancer, diverticular and inflammatory bowel diseases. Mod Pathol 2005 May;18:681-5. http://dx.doi.org/10.1038/modpathol.3800343 